\title{
Transformações da paisagem e o avanço do agronegócio em Gilbués-Piauí
}

\author{
Landscape transformations and agribusiness advances at Gilbués-Piauí
}

\author{
SILVA $^{1}$, I. A. S.
}

ivamauro@hotmail.com

\begin{abstract}
Resumo
O objetivo deste trabalho é analisar a dinâmica da cobertura e do uso das terras, enfatizando as características da paisagem, o processo de apropriação, as transformações da paisagem, os arranjos socioeconômicos e sua articulação com as terras erodidas no município de Gilbués, sudoeste do estado do Piauí. A pesquisa foi elaborada por meio de revisão bibliográfica, trabalhos de campo e compilação de mapas temáticos. Como resultados, o artigo, destaca a ocorrência de erosões, conhecidas como malhadas e grotas, na região centro-sul de Gilbués e na região norte apresenta expansão da agricultura em áreas de Cerrado, caracterizadas por extensões chapadões de topografia plana, que facilita o desenvolvimento e a expansão agrícola. A análise temporal realizada em 1987 e 2009, indicou mudanças conjunturais, como por exemplo, a expansão da área agrícola em áreas de cerrado denso e consequentemente a subtração da cobertura vegetal na região norte, aumento da produtividade. Desta forma, o cerrado situado em Gilbués apresenta distintas formas de cobertura e uso da terra e dilemas socioambientais, que influenciam na configuração e modificações da paisagem.
\end{abstract}

Palavras-chave: Gilbués; transformações da paisagem; expansão agrícola.

\begin{abstract}
The aim of this study is to analyze land cover and land use dynamics, emphasizing landscape characteristics, the appropriation process, landscape transformations and socioeconomic arrangements and their articulation with eroded lands in the municipality of Gilbués, southwest of the state of Piauí. The research was carried out through a bibliographical revision, fieldwork and compilation of thematic maps. As results, the article highlights the occurrence of erosions, known as Badlands, in the south-central region of Gilbués, while the northern region exhibits agriculture expansion in Cerrado areas, characterized by flat topography plateau expanses, facilitating development and agricultural expansion. The temporal analysis carried out in 1987 and 2009 indicated conjunctural changes, such as the expansion of agricultural areas in dense cerrado areas and, consequently, vegetation cover reduction in the northern region and productivity increases. Thus, the Gilbués cerrado presents different forms of land cover and use and socio-environmental dilemmas, which influence landscape configurations and modifications.
\end{abstract}

Key words: Gilbués; landscape transformations; agricultural expansion.

\section{INTRODUÇÃO}

Os cerrados do Piauí caracterizam-se por extensos chapadões de topografia plana, que facilitam a agricultura mecanizada e solos de fácil correção. Esses aspectos, aliados ao baixo preço das terras, vêm atraindo produtores de todo o Brasil (MONTEIRO, 2002; ARAÚJO, 2005; MORAES, 2006). 
Visto como a atual fronteira agrícola do Brasil, conhecida como MATOPIBA, expressão que resulta de um acrônimo criado com as iniciais dos estados do Maranhão, Tocantins, Piauí e Bahia, os cerrados do Piauí atravessam uma fase de integração aos domínios da agricultura moderna.

Essa região constitui-se hoje uma área atrativa para produtores de todo o país devido à grande disponibilidade de terras existentes com preços baixos e facilidade do cultivo agrícola de forma intensiva, uma vez que, face às características físicas do solo, existe a possibilidade de mecanização em larga escala (ARAUJO, 2005).

No município de Gilbués as atividades agrícolas apresentaram uma significativa quantidade na produção de grãos de soja e atualmente se transforma em um produtor de grãos (SILVA, 2014). Vale ressaltar, que a região centro-sul de Gilbués apresenta problemas relacionados aos processos erosivos conhecidos pela literatura científica como desertificação e denominados localmente como malhadas e grotas.

A região norte do município, apontada mais recentemente como nova fronteira agrícola tem seu uso do solo vinculado à agricultura mecanizada e vem ocasionando mudanças conjunturais em ritmo acelerado, desde as últimas décadas do século passado, no município. Essa mudança vem acompanhada de uma intensa transformação das paisagens naturais, como exemplo claro, verifica-se a substituição das paisagens originais (cerrado denso) por extensos campos de cultivo e pastagens.

Portanto, verifica-se na paisagem de Gilbués uma complexa problemática, representada pelos diferentes usos territoriais, referentes à cobertura e ocupação das terras. A região norte, por exemplo, apresenta expansão da agricultura mecanizada e já o setor centro-sul sofre com as consequências dos processos erosivos, circunstância que inviabiliza o uso das terras neste setor do município.

As transformações da paisagem, ocorreram a partir de 1980, quando as atividades econômicas sofreram alterações em consequência da abertura de fronteiras agrícolas no sul do Maranhão, oeste da Bahia e Leste do Tocantins, avançando até a região norte do município de Gilbués (SALES, 1997; SILVA e BARROS, 2016).

Em Gilbués, as características da paisagem propiciam as condições para a expansão de atividades agrícolas do tipo comercial, sendo praticada em grandes extensões de terras nas chapadas dos cerrados, áreas que antes desse processo não eram utilizadas para fins agrícolas. Atualmente, a soja e milho são as culturas permanentes que apresentam maior quantidade produzida e as atividades de pecuária são praticadas de forma intensiva nos chapadões e extensiva nas áreas de malhadas. 
Desta forma, o conhecimento da paisagem e como elas foram ocupadas pelas atividades produtivas, permite discutir as formas de apropriação e uso da terra, em especial com o processo de modernização agropecuária, que recentemente marcou em Gilbués a consolidação dos espaços destinados à produção agrícola de caráter estritamente comercial.

Nessa perspectiva, pretende-se, aqui, enfocar as dinâmicas da ocupação e uso das terras, enfatizando também as características geombientais, as principais alterações econômicas que ocorreram em Gilbués, para analisar o papel dos ciclos econômicos nas transformações da paisagem e sua relação com os condicionantes naturais e a fragilidade ambiental.

\section{PROCEDIMENTOS METODOLÓGICOS E OPERACIONAIS}

Esta pesquisa foi estruturada e construída a partir de três momentos distintos interligados entre si: revisão bibliográfica, elaboração de mapas temáticos, coleta de dados primários e secundários e da realização de trabalhos de campo, procedimentos fundamentais para obtenção dos resultados da pesquisa.

Concomitantemente, foram consultas aos dados agropecuários dos órgãos governamentais em nível federal e estadual no que se refere às atividades econômicas. Os mapas foram elaborados a partir de dados secundários, de informações georreferenciadas e utilização de ferramentas dos Sistemas de informações Geográficas (SIG), tais como ArcGIS e SPRING, exemplificados no quadro 1.

Quadro 1 - Compilação de mapas temáticos. Organização: Ivamauro Ailton de Sousa Silva.

\begin{tabular}{|c|l|l|}
\hline Mapas temáticos & Bases de dados & \multicolumn{1}{c|}{ Procedimentos } \\
\hline \multirow{2}{*}{ Solos } & IBGE e EMBRAPA & $\begin{array}{l}\text { Base cartográfica elaborada conforme dados de solos do IBGE } \\
\text { 2007, inserida no SIG, conforme as classes propostas pelo } \\
\text { EMBRAPA, utilizando também procedimentos e Software } \\
\text { diferenciados. }\end{array}$ \\
\hline \multirow{5}{*}{ Topografia } & IBGE & $\begin{array}{l}\text { Foram utilizadas imagens do Projeto Topodata, que são de uma } \\
\text { refinação das imagens SRTM com resolução de 90 metros para } \\
30 \text { metros. Das imagens foram extraídos dados de altitude, } \\
\text { declividade e relevo sombreado das imagens de órbita 09S465 e } \\
\text { 09S45_, que foram mosaicadas e recortadas para a área de } \\
\text { estudo. }\end{array}$ \\
\hline & $\begin{array}{l}\text { Foram gerados a partir de imagens adquiridas junto ao Instituto } \\
\text { de Pesquisas Espaciais (INPE) através do satélite Landsat 5, } \\
\text { sensor TM, de órbita ponto 220/060 e 220/067, de 29 de }\end{array}$ \\
\hline
\end{tabular}




\begin{tabular}{|c|c|l|}
\hline $\begin{array}{c}\text { Cobertura e uso das } \\
\text { terras }\end{array}$ & $\begin{array}{c}\text { Classificação } \\
\text { digital da imagem } \\
\text { Landsat 5 }\end{array}$ & $\begin{array}{l}\text { setembro de 1987 e 19 de setembro de 2009 - considerando a } \\
\text { disponibilidade de imagens com boa qualidade (sem cobertura } \\
\text { de nuvens). }\end{array}$ \\
\hline $\begin{array}{c}\text { Delimitação das } \\
\text { classes (Agricultura }\end{array}$ & $\begin{array}{c}\text { IBGE e INPE } \\
\text { (Land Sat 5) }\end{array}$ & $\begin{array}{l}\text { Gerados a partir da base cartográfica do IBGE e dados obtidos } \\
\text { pelo Sistema Nacional de Dados Ambientais }\end{array}$ \\
\hline
\end{tabular}

2.1 Caracterização da área: localização, aspectos geoambientais e socioeconômicos

O município de Gilbués, localiza-se no sudoeste do estado do Piauí (Figura 1), na região Nordeste do Brasil, sendo que sua sede municipal se encontra a $742 \mathrm{~km}$ da capital Teresina. De acordo com dados da estimativa populacional do Instituto Brasileiro de Geografia e Estatística (IBGE, 2010), a população é de 10.429 habitantes, distribuídos em um território de área total de $3.495 \mathrm{~km}^{2}$, o que resulta numa densidade demográfica de 2,94 hab./km².

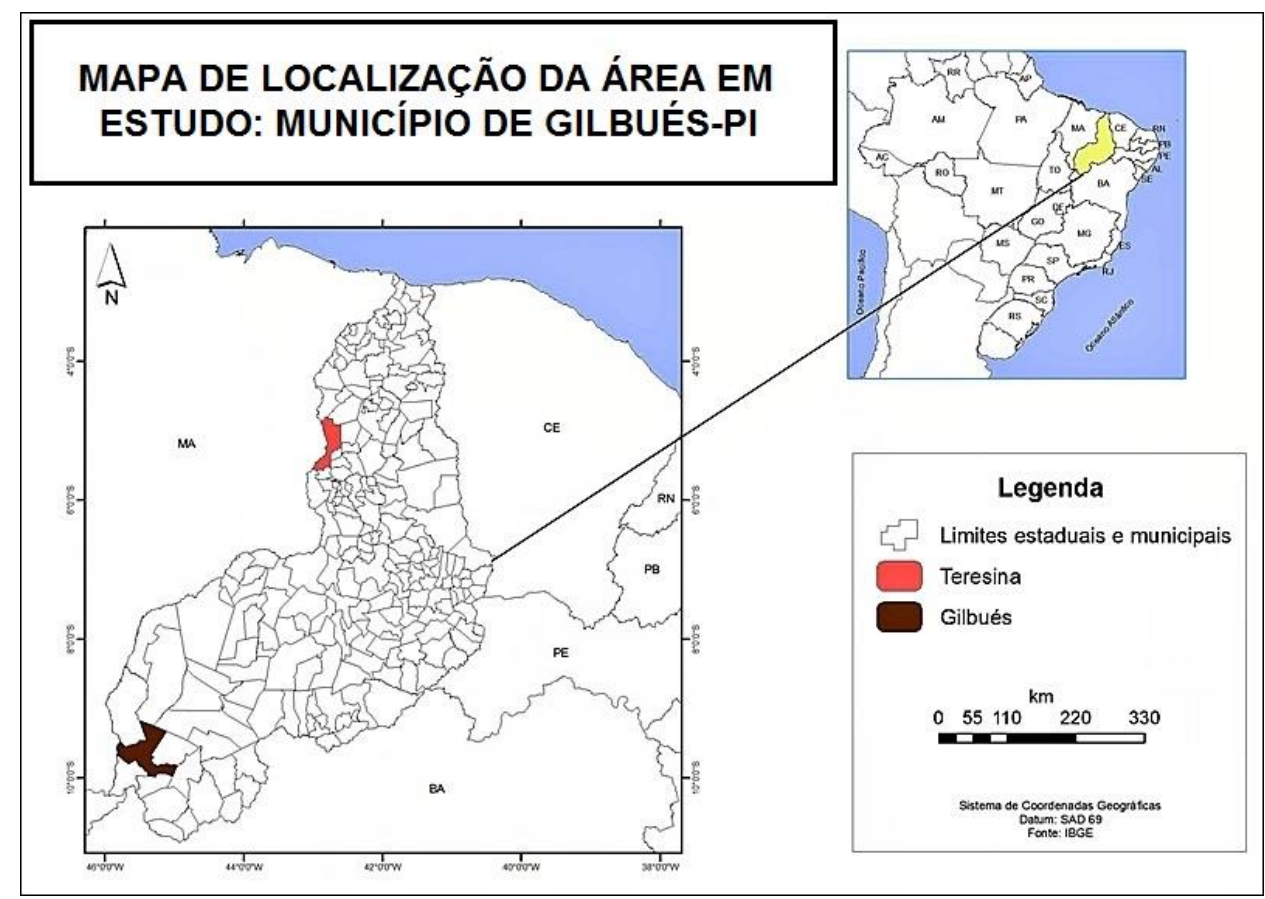

Figura 1 - Mapa de localização da área de estudo - município de Gilbués-Piauí. Fonte: SILVA, 2014.

Conforme Silva (2014) a litologia de Gilbués é representada por formações, cujas idades vão do Paleozoico inferior ao Mesozoico Superior. Os terrenos Paleozoicos estão assentados na Bacia Sedimentar do Parnaíba concebidos pelas formações Sambaíba, Pedra de Fogo, Piauí e Poti e os Mesozoicos na Bacia do São Francisco representados pelas formações geológicas Areado e Urucuia (Figura 2). 


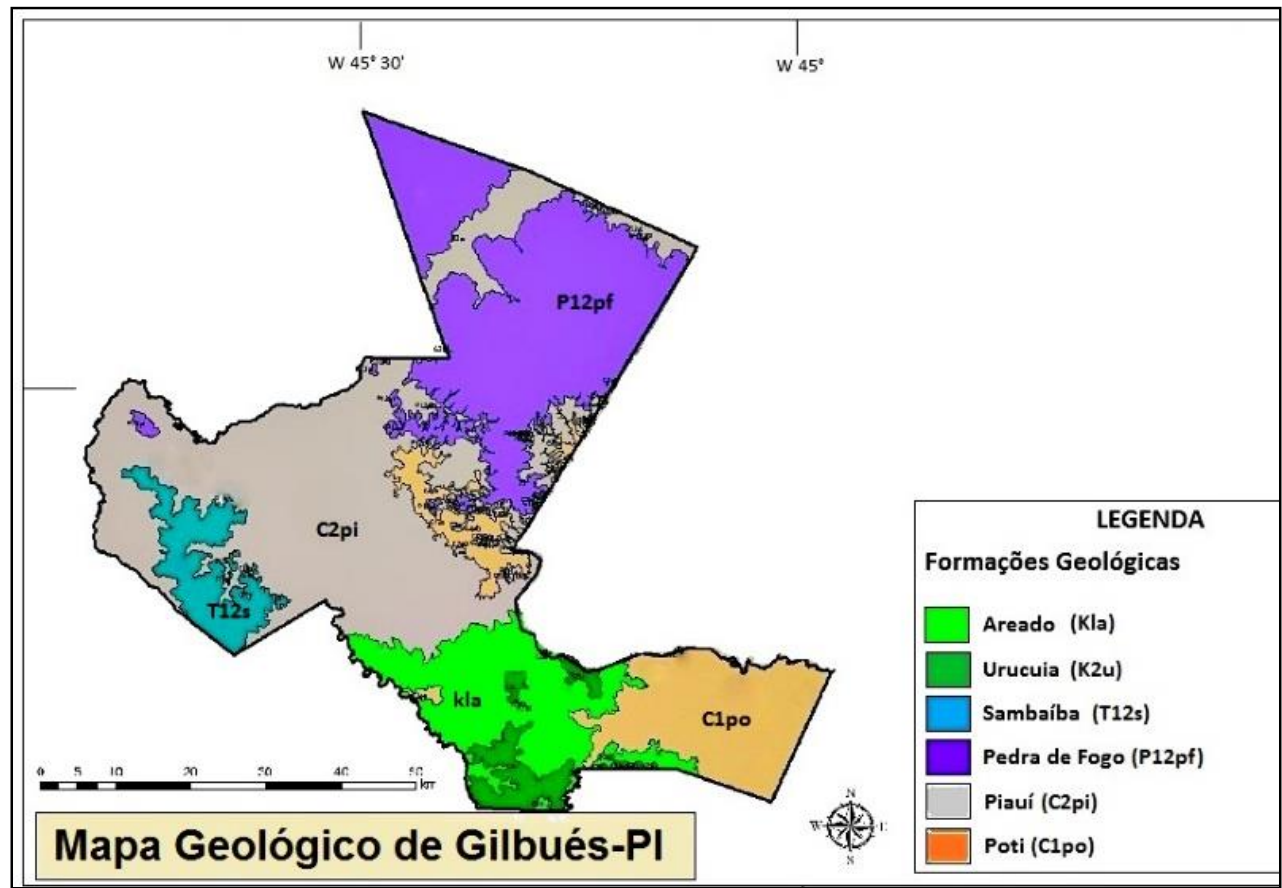

Figura 2 - Mapa de formações geológicas do município de Gilbués. Fonte: CREPANI et. al. 2008.

Em escala regional a formação Piauí e Pedra de Fogo são as litologias predominantes e ocupam grande parte da porção centro-oeste e norte de Gilbués. Na sequência, a formação Poti e Areado, ocupam a porção sul região de Gilbués, as formações litológicas Urucuia e Sambaíba são unidades de menor representatividade na área em estudo.

Segundo Sales (2003) as características geológicas de Gilbués, destacam-se por apresentar litologias extremamente vulneráveis à erosão, representadas basicamente por siltitos, arenitos, argilitos, calcário e conglomerados distintos.

Conforme Embrapa (2009) os principais tipos de solos são: Latossolo Amarelo, Argissolo vermelho amarelo, Neossolo Quartzarênico e Neossolo litólico (Figura 3). Na área de abrangência do município, o Latossolo amarelo tem predomínio absoluto na região norte, assentados em terrenos da formação Pedra de Fogo, ocorrem principalmente nas chapadas/relevo tabular. Os Neossolos Quartzarênicos Hidromórficos ocorrem em áreas topograficamente mais rebaixadas próximas aos corpos hídricos, classe de solo situada na porção oeste de Gilbués, estão assentados na Formação Piauí. Segundo Crepani et. al. (2008) os Neossolos Quartzarênicos são solos de textura arenosa e por isso excessivamente drenados, pobres em nutrientes/matéria orgânica e muito profundos. 


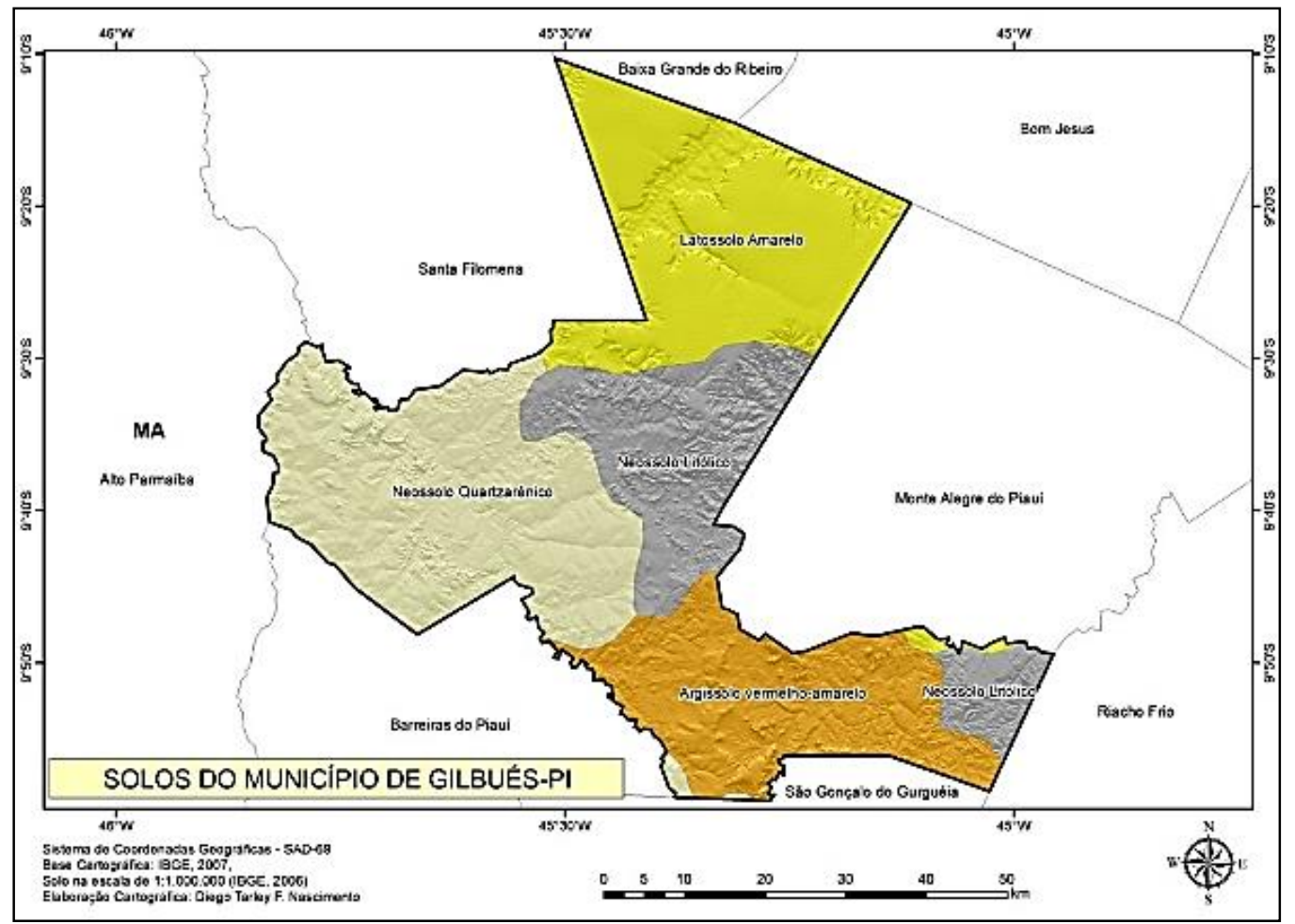

Figura 3 - Mapa de solos do município de Gilbués. Fonte: SILVA, 2014.

Na região nordeste e leste ocorre o Neossolo Litólicos, solos com pavimento pedregoso que não pode ser facilmente removido, localizados em terrenos escarpados. Os Argissolos Vermelho-Amarelo predominam na região centro sul, em áreas dissecadas e relevo suave e ondulado, estão assentados principalmente na Formação Areado e na Formação Urucuia, ocorrendo uma pequena distribuição na Formação Poti.

No contexto regional, o relevo do sudoeste piauiense, envolve uma sequência de blocos orográficos que se caracterizam pelo predomínio de chapadões, feições residuais de morros, morrotes com topos planos e encostas escarpadas decorrentes da erosão regressiva e recuo das escarpas e também compartimentos dissecados (SILVA, 2014, p.77). A área de estudo se encontra numa altitude média de $481 \mathrm{~m}$ e altimetria que varia entre 297 metros (Vale do rio Gurguéia) a 665 metros de altitude (chapadas do Uruçuí) como mostra a figura 4. 


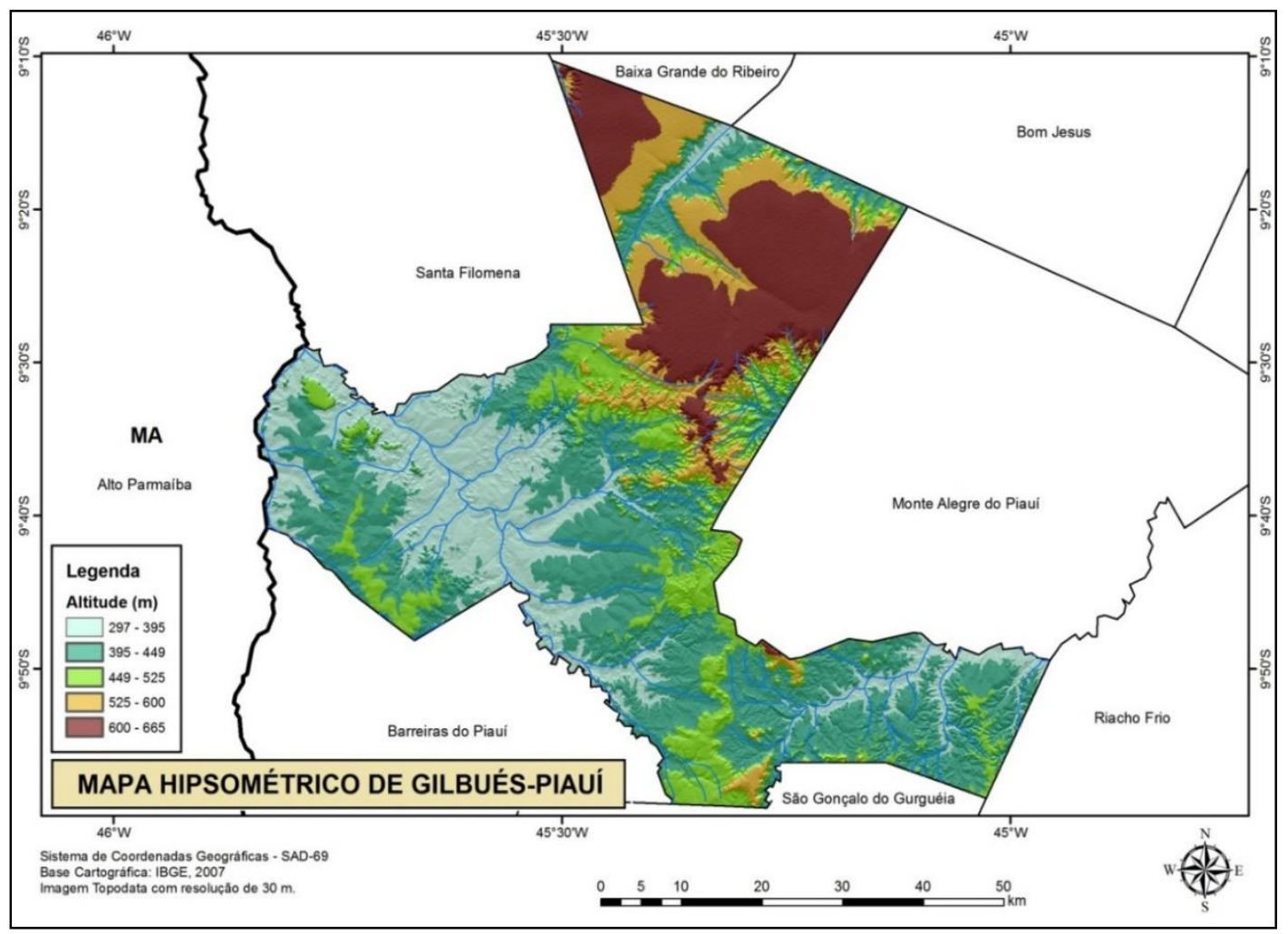

Figura 4 - Mapa hipsométrico do município de Gilbués. Fonte: SILVA, 2014.

A rede hidrográfica está representada pelos altos cursos dos rios Parnaíba, Uruçuí Vermelho, Uruçuí Preto e Gurguéia, com drenagem relativamente densa e perene, além de outros corpos hídricos que devido à sazonalidade climática da região são de regime intermitente: riachos Boqueirão, Santa Maria, Cavalos, Urucuzal, Marmelada e Sucuruiu (SILVA, p. 81, 2014).

Para Ab'Saber (2003) as bacias difusas do Alto Parnaíba, no qual, incluí a região do município de Gilbués, são caracterizadas pela predominância quase absoluta do domínio florístico da savana, também conhecido como domínio fitogeográfico do Cerrado. Quanto à cobertura vegetal, conforme Silva $(2014$, p. 83) há predomínio de diferentes características fitofisionômicas de Cerrado (Cerradão, Campo Sujo e Limpo, Sensu Stricto, Campo Cerrado, Mata Galeria e Veredas).

Conforme a classificação de Köppen, o clima predominante é o subúmido (Tropical chuvoso com seca no inverno) com 4 a 5 meses de estiagem. A pluviosidade média anual é definida pelo regime tropical continental, apresentando, segundo Silva (2014) totais pluviométricos em torno de $1.200 \mathrm{~mm}$, se caracterizando por uma ampla variação e excepcionalidades no regime e ritmo das chuvas. Os totais pluviométricos concentram-se entre os meses de outubro a abril (Figura 5). 


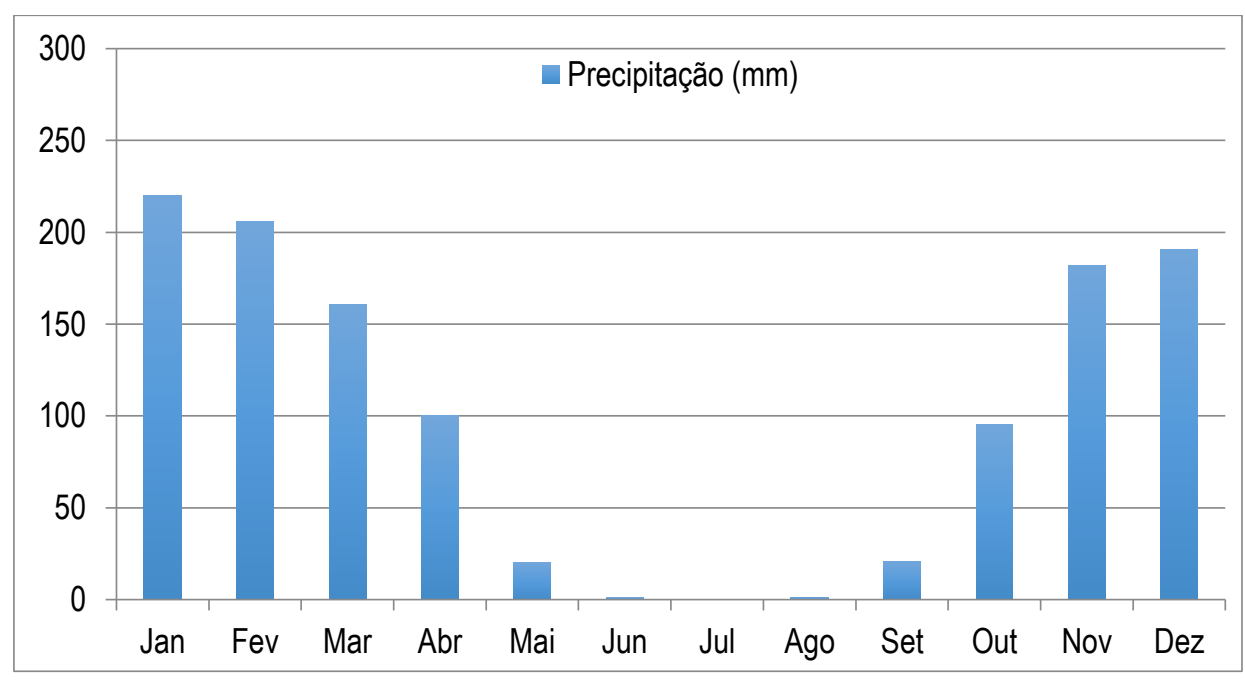

Figura 5 - Gráfico de pluviosidade média (1964-1999). Fonte: SILVA, 2014.

\section{RESULTADOS E DISCUSSÕES}

Por meio das técnicas de processamento digital aplicadas às imagens orbitais de 2009, foi possível obter valores percentuais e distribuição das classes de uso e cobertura das terras para fins de identificação da ocorrência de áreas degradadas.

Para elaboração dos mapas de Cobertura e Uso do Solo, as imagens foram georreferenciadas, mosaicadas e recortadas com base no limite municipal de Gilbués. Em seguida, foram submetidas à classificação não supervisionada, sendo posteriormente tratadas e definidas as seguintes classes de cobertura e uso do solo: cerrado denso, cerrado ralo, agropecuária, solo exposto, areais, área urbana e corpos hídricos, descritas no quadro 2.

Quadro 2 - Classes representadas no mapa de cobertura e uso do solo. Organização: Ivamauro Ailton de Sousa Silva.

\begin{tabular}{|l|l|}
\hline \multicolumn{1}{|c|}{ CLASSES } & \multicolumn{1}{|c|}{ DESCRIÇÃO } \\
\hline Cerrado denso & $\begin{array}{l}\text { Compreende as fisionomias denominadas de Cerradão e Mata Galeria, desenvolvida } \\
\text { em solos profundos e sobre áreas de influência direta da umidade proporcionada por } \\
\text { corpos d'água. }\end{array}$ \\
\hline Cerrado ralo & $\begin{array}{l}\text { Cobertura vegetal constituída por gramínea intercalada por arbustos, bastante } \\
\text { espaçados entre si, sobre denso tapete de vegetação rasteira }\end{array}$ \\
\hline Agropecuária & $\begin{array}{l}\text { Áreas de instalação do agronegócio: grandes áreas ocupadas pela agricultura moderna } \\
\text { em contato com extensões tomadas pela pecuária. Localiza-se nas áreas planas das } \\
\text { chapadas }\end{array}$ \\
\hline Solo exposto & $\begin{array}{l}\text { Áreas que exibem padrão de resposta espectral com pouquíssima cobertura vegetal } \\
\text { (vegetação rasteira) composta por gramíneas }\end{array}$ \\
\hline
\end{tabular}




\begin{tabular}{|c|l|}
\hline $\begin{array}{c}\text { Areal } \\
\text { (malhadas/grotas) }\end{array}$ & $\begin{array}{l}\text { Áreas que apresentam nenhuma participação do componente vegetação e exibe } \\
\text { elevada deposição de sedimentos }\end{array}$ \\
\hline
\end{tabular}

A tabela 1, explicita a quantificação das classes mapeadas e enquanto os mapas constituídos pelas figuras 6 e 7, representam os mapas de cobertura e uso do solo do município de Gilbués referentes aos anos de 1987 e 2009.

Tabela 1 - Área e proporção das classes de cobertura e uso do solo de Gilbués em 1987 e 2009. Organização: Ivamauro Ailton de Sousa Silva

\begin{tabular}{|c|c|c|c|c|}
\hline \multirow{2}{*}{$\begin{array}{c}\text { Classe de Cobertura e } \\
\text { Uso do solo }\end{array}$} & \multicolumn{2}{|c|}{1987} & \multicolumn{2}{|c|}{ Propos } \\
\cline { 2 - 5 } & Área & Proporção (\%) & \multicolumn{2}{|c|}{ Área } \\
\hline Cerrado Denso & $1.725,41$ & 49,37 & $1.295,40$ & 37,07 \\
\hline Cerrado Ralo & $1.058,66$ & 30,29 & $1.215,02$ & 34,76 \\
\hline Agropecuária & 366,41 & 10,48 & 538,55 & 15,41 \\
\hline Solo Exposto & 222,56 & 6,37 & 288,59 & 8,26 \\
\hline Areais (malhadas e grotas) & 121,90 & 3,49 & 157,39 & 4,50 \\
\hline
\end{tabular}

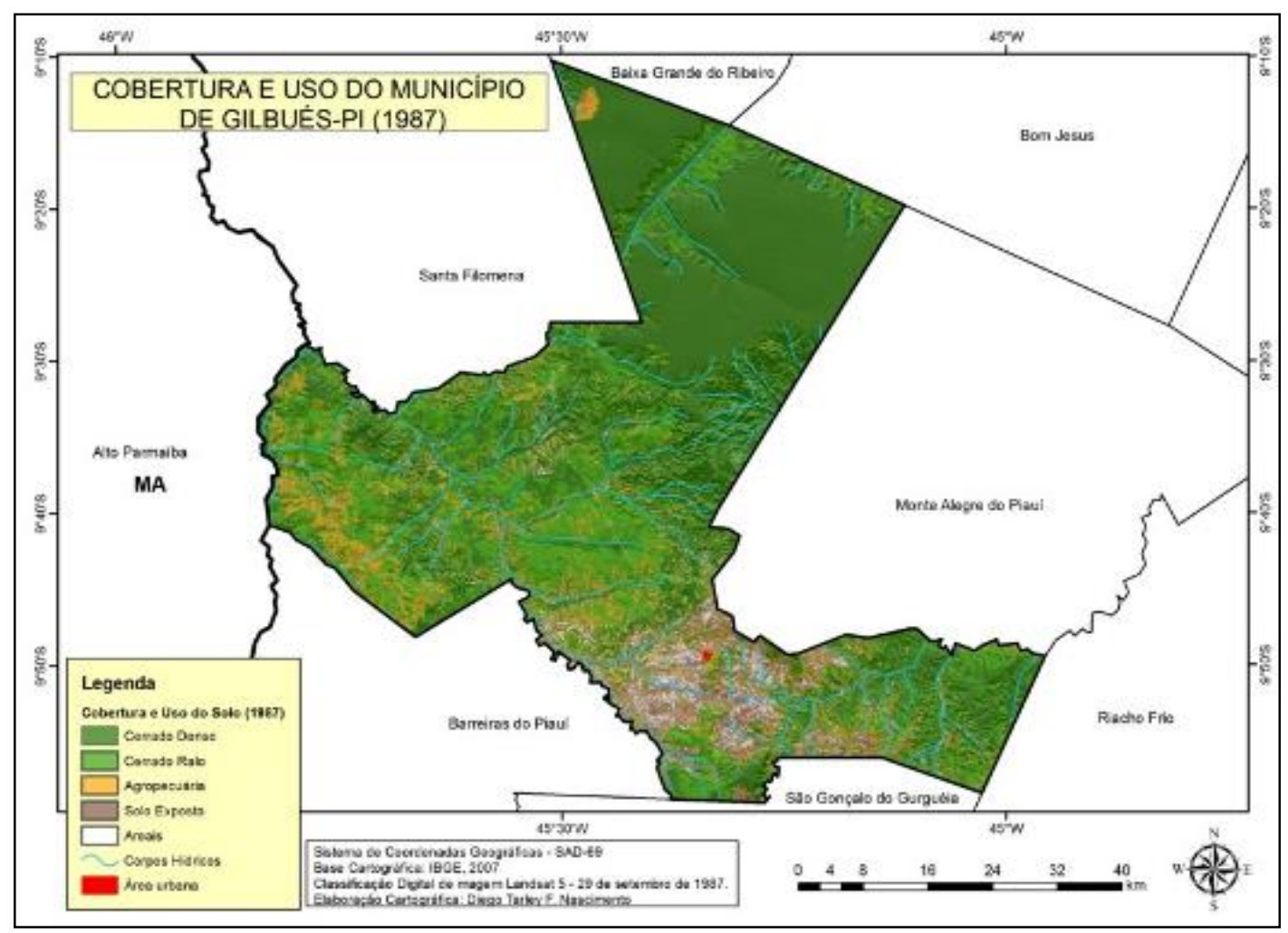

Figura 7 - Mapa de cobertura e uso das Terras do munícipio de Gilbués em 1987. Fonte: SILVA, 2014. 


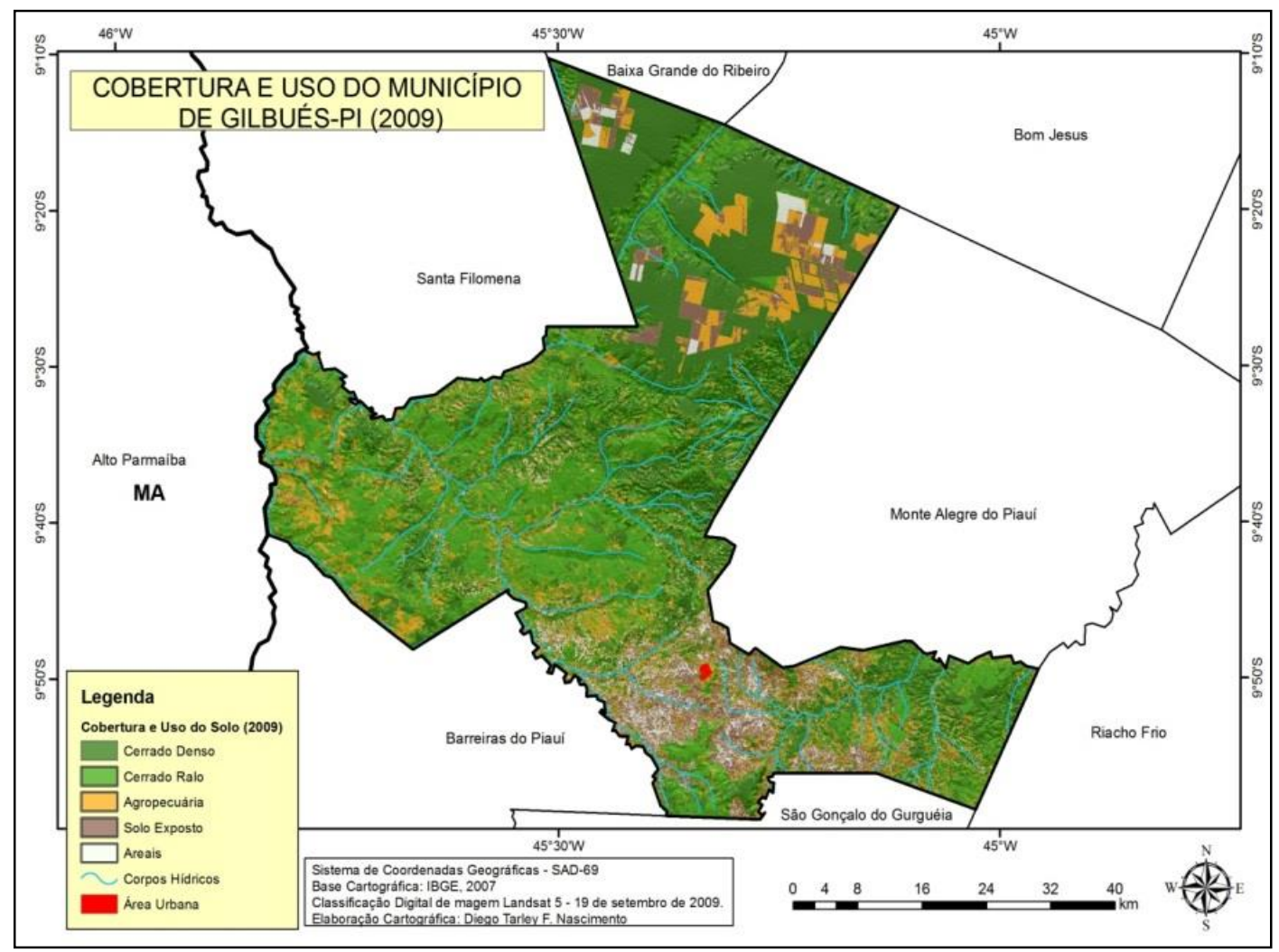

Figura 8 - Mapa de cobertura e uso das Terras do munícipio de Gilbués em 2009. Fonte: SILVA, 2014.

Pela análise dos mapas, observa-se que a área com atividades agropecuárias ocupava, em 1987, uma área relativamente irrisória (cerca de 10,48\% do território), ao passo que, em 2009, essas atividades chegaram a ocupar 15,41\% da área total do município de Gilbués.

Já em relação ao cerrado denso, que em 1987 ocupava uma área de 49,37\%, apresentouse reduzido no ano de 2009, passando a representar 37,07\% da área municipal, uma diminuição de 12,03\%. Devido à expansão da agropecuária, entre 1987 e 2009, ocorreu a perda de 16,5\% da vegetação natural (cerrado denso e ralo). Isso corrobora a ideia de que a agropecuária se utiliza das áreas de vegetação natural para se expandir.

Em consequência da abertura de fronteiras agrícolas em áreas de cerrados, o quadro econômico de Gilbués passou a sofrer algumas alterações, relacionadas, principalmente, à expansão da agricultura e ao volume da produção agrícola. Esse incremento nas áreas de atividades agrícolas, cuja quantificação foi levantada pelo SIG, é corroborado pelos dados da produção agrícola que constam no levantamento do IBGE, indicados na tabela 2. 
Tabela 2 - Dados econômicos - Lavoura Permanente e temporária de Gilbués. Fonte: IBGE - Produção Agrícola Municipal.

\begin{tabular}{|c|c|c|c|c|}
\hline & \multicolumn{2}{|c|}{1990} & \multicolumn{2}{c|}{2009} \\
\hline Lavoura Temporária & $\begin{array}{c}\text { Área plantada } \\
\text { (hectares) }\end{array}$ & $\begin{array}{c}\text { Quantidade produzida } \\
\text { (tonelada) }\end{array}$ & $\begin{array}{c}\text { Área plantada } \\
\text { (hectares) }\end{array}$ & $\begin{array}{c}\text { Quantidade } \\
\text { produzida (tonelada) }\end{array}$ \\
\hline Arroz (em casca) & 360 & 91 & 4.015 & 10.800 \\
\hline Fava (em grão) & 8 & 1 & 10 & 4 \\
\hline Feijão (em grão) & 130 & 10 & 300 & 120 \\
\hline Mandioca & 150 & 1.225 & 250 & 12.000 \\
\hline Milho (em grão) & 240 & 30 & 2.000 & 26.993 \\
\hline Soja (em grão) & 0 & 0 & 8.820 & \\
\hline
\end{tabular}

A expansão da agropecuária ocorreu principalmente na região norte de Gilbués, que apresenta características físico-naturais favoráveis para o desenvolvimento agrícola, tais como: radiação solar abundante, características pedológicas como textura média, porosidade, profundidade e propriedades (acidez) que permitem sua correção através da introdução de calcário, potássio, magnésio, topografia plana e baixa declividade, e ainda condições climáticas (ausência de temperaturas baixas, quantidade de chuva distribuição pluviométrica).

Aliado a esses fatores, a abundância e disponibilidade hídrica (grande potencial de águas subterrâneas e de superfície, com rios perenes como o Uruçuí Preto e Parnaíba) e o baixo preço da terra, com valores inferiores ao dos cerrados do restante do país, segundo Monteiro (2002) foram condicionantes preponderantes para a ocupação e uso do cerrado piauiense principalmente, a expansão da agricultura em Gilbués.

\section{CONSIDERAÇÕES FINAIS}

A pesquisa mostrou que o município de Gilbués apresenta distintas formas de uso da terra, de um lado, a região Norte, tem-se o crescimento do agronegócio, com a produção voltada para a comercialização e exportação de grãos e ao centro-sul, tem-se como predominante a pecuária extensiva que ocorre sob terras frágeis e, em condições climáticas e morfopedológicas favoráveis a intensificação dos processos erosivos denominados localmente de malhada/grotas.

Por meio do estudo relacionado ao uso e ocupação das terras em Gilbués, foi possível identificar atividades econômicas que influenciam fortemente nas transformações da paisagem e principalmente na organização espacial, em última instância, refletem as formas de relação entre a sociedade e seus recursos naturais. 
As atividades da agricultura mecanizada, desenvolvida desde o início de 1980 e que tem despertado o interesse de produtores rurais capitalizados e empresas agrícolas através da expansão das fronteiras agrícolas já instaladas no sul do Maranhão e oeste Baiano e recentemente vem sendo desenvolvida na região norte de Gilbués, espaço geográfico com predomínio de relevo tabular com topografia plana, propriedades físicas do solo, abundância hídrica e condições climáticas adequadas para o desenvolvimento de práticas agrícolas em larga escala.

Com relação à dinâmica da cobertura e uso da terra, é possível destacar o aumento da agropecuária e a diminuição das áreas revestidas por vegetação densa dando espaço à implementação de atividades agrícolas. Esse avanço da agropecuária sobre o Cerrado piauiense é visto como fator de desenvolvimento da região e, mais recentemente, tem tido papel importante na retomada do crescimento econômico do nordeste brasileiro, na medida em que o agronegócio amplia sua participação no mercado externo, via exportação de produtos como a carne bovina e a soja.

Em função dos aspectos apresentados nesta pesquisa e considerando a fragilidade da paisagem em relação com atual dinâmica e uso das terras, recomenda-se: a) transformar o espaço onde ocorrem as malhadas e grotas em área de preservação ambiental; b) evitar práticas mecânicas que promovem grande compactação e mobilização do solo; c) prevenir prática de pecuária (superpastejo) acima da capacidade de suporte do ambiente; d) combater a utilização do fogo nas áreas de malhadas/solo exposto que venham proporcionar maior sensibilidade ao solo (ressecamento); e, e) promover pesquisas interdisciplinares com interfaces entre outras áreas do conhecimento (Agronomia, Ecologia, Biologia e Sociologia);

É imprescindível realizar análises regionais e locais, em escalas apropriadas e compatíveis, levando-se em consideração a grande diversidade climática, geológica, morfopedológica e fitogeográfica da região. Os recursos da tecnologia e a utilização dos sistemas de informações geográficas podem ser de grande contribuição.

Assim, com o desenvolvimento desta pesquisa, pode-se buscar compreender a trajetória histórica da ocupação das terras, as atuais dinâmicas socioeconômicas realizadas no Cerrado Piauiense e os dilemas ambientais ocorridos especificamente no município de Gilbués, que testemunhou mudanças significativas e vivenciadas ao longo do tempo e espaço, na paisagem do sudoeste piauiense. 


\section{REFERÊNCIAS}

ABREU, I. G. e NUNES, M. C. P. Vilas e cidades do Piauí. In: Raimundo Nonato Monteiro de Santana (Org). Piauí: formação, desenvolvimento, perspectivas: Teresina: Halley. 462p. 1995.

AB'SÁBER, A. N.. Os domínios de Natureza no Brasil: potencialidades paisagísticas. São Paulo: Ateliê Editorial. p. 83-100. 2003.

ARAÚJO, A. A. Modernização na fronteira agrícola dos cerrados piauienses: o caso de Bom Jesus: UFPI, Teresina. 164 p. 2005.

CREPANI, E.; MEDEIROS J.S. de; PALMEIRA, A.F.; SILVA, E. F. da - Relatório do Banco de Dados Geográficos de parte do Núcleo de Desertificação de Gilbués. INPE: São José dos Campos, 2008.

EMPRESA BRASILEIRA DE PESQUISA AGROPECUÁRIA, 2009 - Embrapa Meio Norte Disponível em http://www.cpamn.embrapa.br/

INSTITUTO BRASILEIRO DE GEOGRAFIA E ESTATÍSTICA - IBGE. PESQUISA PECUÁRIA MUNICIPAL DE GILBUÉS, 2009.

INSTITUTO BRASILEIRO DE GEOGRAFIA E ESTATÍSTICA. Censo Demográfico de 2010 - município de Gilbués: características da população e dos domicílios. Disponível em www.cidades.ibge.gov.br/

MONTEIRO, M. S. L. Ocupação do cerrado piauiense: estratégia empresarial e especulação fundiária. Tese (Doutorado em Economia Aplicada) - Universidade Estadual de Campinas, São Paulo, 2002.

MORAES, M. D. C. Do destino pastoril à vocação agrícola: modernização agrícola dos cerrados e inflexões discursivas nas narrativas mestras do Piauí .In: Difusão do agronegócio e novas dinâmicas socioespaciais. ELIAS, D., PEQUENO, R. (Org), Fortaleza: Banco do Nordeste do Brasil. 484p. 2006.

SALES, M. C. L. Estudo da degradação ambiental em Gilbués-PI: Reavaliando o "núcleo de desertificação”. São Paulo, USP. Dissertação de Mestrado - Geografia. 181p. 1997

SALES, M. C. L. Degradação Ambiental em Gilbués, Piauí. Revista Mercator, Fortaleza, v. 2, n. 4, p. 115-124, 2003.

SILVA, I. A. S.; Clima e arenização em Gilbués-Piauí: dinâmica das precipitações e a vulnerabilidade da paisagem aos eventos pluviais intensos. Dissertação de Mestrado em Geografia: Universidade Federal de Goiás, Goiânia. 2014.

SILVA, I. A. S.; BARROS, J. R. degradação ambiental, cobertura e uso das terras: uma análise geográfica do município de Gilbués-Piauí. Revista Equador (UFPI), Teresina, v. 5, n. 2, p. 190204, 2016. 


\section{AGRADECIMENTOS}

À Coordenação de Aperfeiçoamento de Pessoal de Nível Superior (CAPES) pela atual concessão de bolsa no Doutorado na Universidade Federal do Rio Grande do Sul.

Recebido em: 13/08/2019

Aceito para publicação em: 01/11/2019 